\title{
A 10-point plan for avoiding hyaluronic acid dermal filler-related complications during facial aesthetic procedures and algorithms for management
}

Clinical, Cosmetic and Investigational Dermatology

\author{
Izolda Heydenrych ${ }^{1,2}$ \\ Krishan M Kapoor ${ }^{3,4}$ \\ Koenraad De Boulle 5 \\ Greg Goodman ${ }^{6,7}$ \\ Arthur Swift ${ }^{8}$ \\ Narendra Kumar9 \\ Eqram Rahman ${ }^{10}$
}

'Cape Town Cosmetic Dermatology Centre, Central Park on Esplanade, Century City, Cape Town, South

Africa; ${ }^{2}$ Division of Dermatology, Faculty of Medicine and Health

Sciences, Stellenbosch University,

Stellenbosch, South Africa;

${ }^{3}$ Department of Plastic Surgery, Fortis Hospital, Mohali, India; ${ }^{4}$ AntiClock

Clinic, Chandigarh, India; ${ }^{5} \mathrm{Aalst}$

Dermatology Clinic, Aalst, Belgium;

${ }^{6}$ Department of Primary Heath

Care, Monash University, Clayton,

Victoria, Australia; ${ }^{7}$ Skin and Cancer

Foundation Inc, Clayton, Victoria,

Australia; ${ }^{8}$ Westmount Institute of

Plastic Surgery, Montreal, Canada;

${ }^{9}$ Faculty of Medical Science, Anglia

Ruskin University, Chelmsford, UK;

${ }^{10}$ Institute of Medical and Biomedical

Education, St George's University of

London, London, UK

Correspondence: Izolda Heydenrych Cape Town Cosmetic Dermatology Centre, Central Park on Esplanade, Postnet Suite 136, Century City, Cape Town 7442, South Africa

Tel +27215527220

Fax +27 215527229

Email izoldaheydenrych@gmail.com
Abstract: The recent rapid growth in dermal filler use, in conjunction with inadequate product and injector control, has heralded a concerning increase in filler complications. The 10-point plan has been developed to minimize complications through careful preconsideration of causative factors, categorized as patient, product, and procedure related. Patient-related factors include history, which involves a preprocedural consultation with careful elucidation of skin conditions, systemic disease, medications, and previous cosmetic procedures. Other exclusion criteria include autoimmune diseases and multiple allergies. The temporal proximity of dental or routine medical procedures is discouraged. Insightful patient assessment, with the consideration of ethnicity, gender, and generational needs, is of paramount importance. Specified informed consent is vital due to the concerning increase in vascular complications, which carry the risk for skin compromise and loss of vision. Informed consent should be signed for both adverse events and their treatment. Product-related factors include reversibility, which is a powerful advantage when using hyaluronic acid (HA) products. Complications from nonreversible or minimally degradable products, especially when layered over vital structures, are more difficult to control. Product characteristics such as HA concentration and proprietary cross-linking should be understood in the context of ideal depth, placement, and expected duration. Product layering over late or minimally degradable fillers is discouraged, while layering of HA of over the same brand, or even across brands, seems to be feasible. Procedural factors such as photographic documentation, procedural planning, aseptic technique, and anatomical and technical knowledge are of pivotal importance. A final section is dedicated to algorithms and protocols for the management and treatment of complications such as hypersensitivity, vascular events, infection, and late-onset nodules. The 10-point plan is a systematic, effective strategy aimed at reducing the risk of dermal filler complications.

Keywords: assessment, complications, dermal fillers, prevention, treatment

\section{Introduction}

The use of dermal fillers has experienced tremendous growth over the past years, heralding an increase in more serious adverse events. The field of esthetic fillers is currently enduring an onslaught of factors compromising not only patient safety but also the reputation of the field. Although it is said that the courage of a soldier is heightened by his knowledge of his profession (Publius Flavius Vegetius Renatus), 
in everyday filler practice, it is often the lack of knowledge that emboldens the esthetic physician.

In their review of the regulations of cosmetic interventions, the UK Department of Health cautioned that the use of injectable fillers is a crisis waiting to happen. ${ }^{1}$ This warning was prompted by several factors, including inadequate regulation of esthetic physicians, suboptimal control of filler quality, and the recent rapid growth in the filler market for purely financial gain. These factors warrant proactive intervention not only in the interest of patient safety but also in the interest of maintaining the credibility and viability of the field.

Filler complications are traditionally divided into four categories: allergic, infective, late-onset nodules/inflammation, and intravascular events., ${ }^{2,3}$ The incidence of complications, notably late-onset nodules and intravascular events (eg, skin necrosis and blindness), is increasing. ${ }^{4,5}$ More than 100 cases of blindness are documented in the literature, with most cases reported in recent years. ${ }^{6}$ These complications can be reduced or even prevented by a vigilant, systematic approach. This entails careful patient selection, wise product choice, aseptic technique, and insightful knowledge of facial anatomy coupled with constant awareness of the early signs of vascular compromise. ${ }^{7}$

The 10-point plan (10PP) suggested here is a systematic, effective strategy aimed at reducing the risk of dermal filler complications. It is achieved through conscious awareness and careful preconsideration of the possible confounding factors specific to each procedure (Table 1). The 10PP is also presented in a table form as a quick-reference checklist for both entry-level and experienced esthetic physicians.

Table I A 10-point plan for avoiding filler complications

\begin{tabular}{|c|c|c|c|}
\hline I. Patient & II. Product & III. Procedure & IV. Algorithms \\
\hline $\begin{array}{l}\text { I. History } \\
\text { - Skin conditions } \\
\text { - Systemic disease } \\
\text { - Medication } \\
\text { - Procedures } \\
\text { Selection }\end{array}$ & $\begin{array}{l}\text { 4. Reversibility } \\
\text { - Hyaluronidase } \\
\text { - Dilution + dosage }\end{array}$ & $\begin{array}{l}\text { 7. Photographs } \\
\text { - Pre and post } \\
\text { - Black background } \\
\text { - No makeup } \\
\text { - Rest and animation } \\
\text { - Angles and lighting } \\
\text { - SLR camera }\end{array}$ & $\begin{array}{l}\text { Allergy/hypersensitivity } \\
\text { - Early: vitals, adrenalin, IV } \\
\text { - Late: cold compress } \\
\text { - HI + H2 antagonists } \\
\text { - Oral corticosteroids } \\
\text { - Propanol, ibuprofen }\end{array}$ \\
\hline $\begin{array}{l}\text { - Skin + systemic } \\
\text { - Pretreatment } \\
\text { - Dental, vaccinations }\end{array}$ & $\begin{array}{l}\text { 5. Product characteristics } \\
\text { determine placement } \\
\text { - HA concentration }\end{array}$ & $\begin{array}{l}\text { 8. Procedural planning and aseptic technique } \\
\text { - Technical flow } \\
\text { - Everything at hand }\end{array}$ & $\begin{array}{l}\text { Vascular events } \\
\text { - HDPH } \\
\text { If visual disturbance occurs: } \\
\text { a) Stop injecting } \\
\text { b) Consult an ophthalmologist } \\
\text { c) } 90 \text {-minute timeframe }\end{array}$ \\
\hline $\begin{array}{l}\text { - Routine procedures } \\
\text { - Dysmorphophobia }\end{array}$ & - Cross-linking & $\begin{array}{l}\text { - Skin: chlorhexidine/alcohol } \\
\text { - Chlorhexidine mouthwash } \\
\text { - Gloves + hand washing }\end{array}$ & $\begin{array}{l}\text { Infection } \\
\text { - Oral antibiotics } \\
\text { - IV antibiotics } \\
\text { - Hyaluronidase } \\
\text { - Surgical drainage } \\
\text { - Laser }\end{array}$ \\
\hline $\begin{array}{l}\text { 2. Assessment } \\
\text { - Beauty, aging, gender, } \\
\text { ethnicity } \\
\text { - Wants vs needs }\end{array}$ & \multirow{2}{*}{$\begin{array}{l}\text { 6. Product layering } \\
\text { - HA over minimally } \\
\text { biodegradable fillers }\end{array}$} & $\begin{array}{l}\text { 9. Injection anatomy } \\
\text { - Safety by depth } \\
\text { - Danger areas }\end{array}$ & \multirow[t]{2}{*}{$\begin{array}{l}\text { Late-onset nodules } \\
\text { - Antibiotics } \\
\text { - Hyaluronidase } \\
\text { - Immunosuppressives } \\
\text { - Tacrolimus } \\
\text { - Pimecrolimus } \\
\text { - Colchicine }\end{array}$} \\
\hline $\begin{array}{l}\text { 3. Consent } \\
\text { - Informed consent } \\
\text { - Procedure + complications } \\
\text { - Financial consent }\end{array}$ & & $\begin{array}{l}\text { 10. Technical knowledge } \\
\text { - Depth, placement } \\
\text { - Speed } \\
\text { - Needle vs cannula } \\
\text { - Aspiration vs movement }\end{array}$ & \\
\hline
\end{tabular}

Abbreviations: HA, hyaluronic acid; IV, intravenous; SLR, single-lens reflex. 
The 10 points are further divided into the following three categories:

- Patient-related factors.

- Product-related factors.

- Procedure-related factors.

Algorithms for the management of early, intravascular, and late-onset events are included.

\section{Patient-related factors History and selection}

The patient is not a blank canvas. Whilst they may have requested a procedure, it is the esthetic physician who should ultimately "select" the patient. An understanding of the treatment motivation is thus vital in minimizing inappropriate patient selection. Obtaining a thorough history of skin conditions, allergies, systemic disease, current medication, and previous procedures is mandatory.

Patients should be carefully selected by excluding both cutaneous and systemic contra-indications. Skin barrier disruption due to inflammatory or infective conditions allows the penetration of infective agents. ${ }^{8}$ Rosacea is an inflammatory condition presenting with decreased barrier function and proinflammatory antimicrobial peptides functioning as vasoactive mediators. ${ }^{9}$ In acne, Propionibacterium acnes induces a cytokine-mediated inflammasome in which Toll-like receptor-2 (TLR-2) has been proven to play a role. ${ }^{10}$ There are increased numbers of resistant $P$. acnes at the edges of topically treated acne areas, which may play a role in the formation of biofilms. It is important to realize that the "safe distance" for filler placement relative to an area of acne is unknown. Pretreatment of inflammatory conditions such as acne, rosacea, and dermatitis is important as is allowing adequate time for the restoration of barrier function. ${ }^{9}$ This may require 3-4 weeks after apparent clearance. It is advisable that patients with remote infections involving, for example, the urinary tract, sinuses, intestinal tract, and oral cavity are deferred for treatment as it has been postulated that hematogenous spread of normally non-virulent bacteria may lead to binding to the TLR's with possible triggering of an immune response and formation of late-onset nodules. ${ }^{10}$ It is prudent to note that lateonset nodules may be preceded by viral or flu-like illness. ${ }^{11}$ Prophylactic antivirals to prevent virus reactivation are best considered if there is a history of herpes simplex infection in the intended injection area. ${ }^{12}$ Filler treatments are contraindicated in active autoimmune diseases such as systemic lupus erythematosus, rheumatoid arthritis, mixed connective tissue disease, and Hashimoto's thyroiditis. ${ }^{7,13}$ It is preferable to avoid injecting patients with multiple, severe allergies and a history of anaphylaxis since drug allergies might preclude optimal management of complications. ${ }^{13}$

Knowledge of previous surgical and nonsurgical cosmetic procedures is vital as these could lead to fixation and scarring of underlying vasculature, thus facilitating intravascular placement by both cannulae and needles. Determining the types and location of previously injected products may help to prevent compatibility issues with minimally degradable fillers and the intendant risk of late-onset nodules. ${ }^{14}$ Dental procedures and visits to the oral hygienist are best avoided during the $2-4$-week period before and after filler treatment to reduce the risk of hematogenous bacterial seeding and potential development of biofilm. ${ }^{15}$ Tooth bleaching/whitening frequently implies concomitant dental descaling and should also be discouraged during this period. It is advisable to structure the treatment plan over time, with due consideration to pending medical procedures, dental visits, and immunizations, thus limiting inflammatory reactions or hypersensitivities due to a heightened immune system. $^{7}$

Unrealistic expectations or signs of body dysmorphic disorder are deemed a firm contraindication to cosmetic treatment. $^{1}$

Patients should be given a prefiller checklist serving as an exclusion questionnaire and emphasizing the importance of having no infective or inflammatory conditions (cutaneous or systemic) at the time of treatment. The undesirability of dental and routine medical procedures in the period adjacent to filler treatment should be noted, and facial procedures inducing inflammation or disruption of the skin barrier should likewise be planned away from the time of treatment. The checklist should also include a list of common blood thinners (medications and foodstuffs) to preferably be avoided in the week before treatment (aspirin, nonsteroidal anti-inflammatories, salmon oil, vitamin E, gingko biloba, red wine, dark chocolate, grapefruit, etc). ${ }^{16}$ In the author's clinic, it is a standard practice to contact patients 1 week before planned treatments to ensure that they are in possession of the prefiller checklist, understand the selection criteria, have no precluding factors, and are in possession of scripted antivirals where applicable. Investing adequate time in the initial consultation is pivotal in optimizing both the timing and outcome of the treatment process.

\section{Assessment}

Rapid globalization and an increase in social media use across generations have fundamentally changed patients' 
perceptions of beauty. ${ }^{17}$ Esthetic inclinations vary and the injection specialist should communicate effectively to establish underlying motivations, differentiate between the patients' wants and needs, and temper expectations within realistic goals. ${ }^{18}$ The influence of Fitzpatrick skin type should be considered for potential post-inflammatory hyperpigmentation. ${ }^{19}$

\section{Consent}

Obtaining signed informed consent is crucial in creating awareness and acceptance of the potential risk of filler-induced complications. ${ }^{20}$ Supplying written pre- and post-instructions during the initial consultation can help to establish realistic expectations and minimize legal repercussions. ${ }^{21}$ Moreover, it might be wise to obtain informed consent for the management of inadvertent complications, should they arise, to expedite efficient management. It is advisable to outline the more common adverse events (legally considered $>1 \%$ occurrence) as well as those that are particularly impactful such as skin necrosis and impairment in vision, in the consent form.

Beyond an unnatural look, the three main concerns patient face are pain, complications, and procedural costs. ${ }^{22}$ It is essential to discuss treatment costs, obtain financial consent, and plan over the long term to obviate financial stress. Addressing these issues upfront is instrumental in establishing the trust that underpins true patient satisfaction.

\section{Product-related factors Reversibility}

The reversibility of hyaluronic acid (HA) fillers is a powerful advantage as most complications induced by these fillers can be addressed. ${ }^{23}$ The management of problems with irreversible fillers is far more challenging as no specific dissolving compounds currently exist. These products should ideally be restricted to clinicians with experience in their use. ${ }^{14}$

HA fillers can be liquefied by the use of hyaluronidase, requiring that injection specialists familiarize themselves with the reconstitution and dosage necessary for the treatment of both intravascular complications and cosmetically unsatisfactory results. ${ }^{24-26}$

\section{Product characteristics}

The hygroscopic nature of HA is an important determinant of product-related swelling as higher HA concentrations, associated free HA content, and limited cross-linking result in an increased tissue swelling. ${ }^{27}$ It is important that the esthetic physician differentiates between product-related swelling and tissue trauma. The HA concentration and the extent of cross-linking determine the product's characteristics (viscosity, elasticity, resistance to degradation, $G^{\prime}$ [ $G$ prime/ elastic modulus], $G^{\prime \prime}$ [ $G$ double prime/viscous modulus], and Tan Delta) and ultimately its clinical efficacy at different tissue depths. ${ }^{2,14}$

Every company obtains their raw HA product as disaccharide chains from the same source after which a solvent is added, resulting in a HA liquid with minimal in situ longevity. Crosslinker (typically 1,4-butanediol diglycidyl ether [BDDE]) is therefore added, converting the liquid into a semisolid gel that is too firm for syringe injection. Each company has a proprietary modification process, which allows a portfolio of HA filler consistencies with varied characteristics such as viscosity, gel hardness, lifting ability, and tissue integration. ${ }^{28}$ Therefore, cross-linking characteristics are pivotal in determining the optimal depth of placement and longevity of the product.

\section{Product layering}

A thorough history of previous product use is mandatory. Certain late or minimally biodegradable fillers may be provoked into reactivity by needle trauma alone, or when a second filler such as HA is layered over them, thus inducing long-lasting complications such as foreign body granulomas. ${ }^{7}$ Due to the inherent longevity associated with minimally biodegradable fillers, there is a portended increased incidence in more delayed-onset adverse events. ${ }^{27,29}$ Although HAs remain the most compatible fillers, it is important to proceed with caution when considering cross-brand layering.

\section{Procedure-related factors Photographs}

Photographic records are essential not only for medico-legal purposes but also for critical appraisal of planning and results. They can serve as a major driver for progression to treatment and as an invaluable learning curve for the esthetic physician. ${ }^{3}$ To ensure good quality pre- and posttreatment photographs, remove all makeup and jewelry, use a hairband and preferably a black background. Multiple images at rest and during animation are recommended, including but not limited to anterior, oblique, and lateral views with the head in a neutral, neck-extended, and neck-flexed position..$^{30}$ Proper lighting, consistent angles, and fixed distance from the camera are mandatory. It is advisable to use a single-lens reflex (SLR) camera and tripod rather than mobile cameras as the latter are frequently equipped with wide-angle lenses that may lead to photographic distortion. 


\section{Procedural planning and aseptic technique}

Procedural planning is essential in preventing breaching of the clean workspace. Ensuring that everything is at hand before initiating the treatment helps to reduce breaks in the aseptic field and the concomitant risk of injection-related infections. ${ }^{31}$ As with all esthetic procedures, a preconceived plan aids in a clear procedural flow that minimizes complications.

Stringent aseptic technique is mandatory. ${ }^{32}$ The patient's skin should be cleaned, degreased, and disinfected. There are no universally recommended topical antiseptics, but chlorhexidine, chloroxylenol, iodophors, alcohol, and iodine may be appropriate. Makeup should be removed, and the skin cleansed carefully with $2 \%$ chlorhexidine gluconate in $70 \%$ alcohol, avoiding ocular exposure to the disinfectant. Rinsing the mouth with an antiseptic mouthwash containing chlorhexidine $(0,2 \%)$ or povidone-iodine sterilizes the oral cavity for up to 8 hours and has been suggested as a preventative practice when treating the perioral area or those patients with a lip-licking habit. ${ }^{15}$ The esthetic physician should remove all jewelry, wash their hands with antiseptic cleanser, and use gloves for all cases of injection therapy. ${ }^{33}$ The procedure is not deemed to be sterile as the syringe itself is not completely sterile. Therefore, once the esthetic physician holds the syringe, sterility is lost and aseptic technique is of paramount importance. Transferring the surgical principles of sterile technique by not touching any component of the needle or cannula that penetrates the skin may further reduce the prevalence of infective complications. Constant vigilance against possible contamination is of utmost importance. ${ }^{34}$ Cleansing over a sufficiently broad area is imperative as there is a higher infective risk upon inadvertent resting of the cannula on the adjacent skin. Frequent changing of needles and cannulae is advised when utilizing multiple entry points. ${ }^{35}$

The use of disposable sterile dressing trays with containers for prep solution, gauze, and disposable sterile drapes provides a convenient and inexpensive way to establish a safe, clean work area in an office setting. ${ }^{36}$

\section{Applied facial anatomy}

Knowledge of applied facial anatomy is of paramount importance and serves as the foundation for avoiding disastrous complications. ${ }^{37,45}$ Multiple documented variations and classifications of the vascular arcades in the face render it impossible for the injection specialist to determine the patient's anatomy. There is no $100 \%$ guarantee of avoiding vascular injury once the needle or cannula has penetrated beneath the skin. The location of the tip of the needle or cannula determines the location of the deposition of product and, thus, its embolic potential. Nonetheless, potential danger areas can be identified by clear anatomical understanding of the depth of neurovascular structures across specific facial zones. ${ }^{27}$ Esthetic physicians should fully understand the appropriate depth and plane of injection (safety by depth) at different sites of treatment. ${ }^{6,38}$ Facial injection anatomy training is specific for nonsurgical syringe therapy and is highly advisable for optimal results and avoidance of complications..$^{38}$ However, even expert esthetic physicians have a substantial history of intravascular injection in their careers with $61 \%$ of trainers inducing at least one such episode. ${ }^{39}$

\section{Technical knowledge}

Knowledge of optimal placement and injection depth is cardinal to the esthetic success of dermal fillers. Unduly superficial placement may lead to adverse effects such as surface irregularities and the Tyndall effect. ${ }^{40}$ The hallmarks of sage injection technique include slow injection speed with least amount of pressure and small bolus size. ${ }^{41}$ Although controversial, the merits of aspiration before injection (especially in high-risk areas), vs constant movement of the tip of the needle, should be considered. Incremental injections of $0.1-0.2 \mathrm{cc}$ of the product should be used while continually monitoring the skin of the surrounding area. ${ }^{42}$ Rapid injection speed, aggressive fanning, high-volume filler deposits, and large bolus size induce increased bruisability and the occurrence of delayed inflammatory reactions. ${ }^{40,43}$ The esthetic physician should understand the relative risks and advantages of using a needle vs cannula. Small-bore needles are recommended by some to slow the injection rate, and blunt cannulae are suggested in high-risk regions in an attempt to reduce vessel injury. ${ }^{2}$ Surgery, scarring, or multiple previous procedures may increase the risk of cannulating a vessel. ${ }^{25}$

\section{Algorithms}

\section{Algorithms and protocols}

Complication management and recognition are the most significant unmet needs with HA fillers. ${ }^{2}$ From a temporal perspective, filler complications may be divided into earlyonset (vascular, inflammatory, injection related, placement, and distant spread) and late-onset (inflammatory, nodules, 
dyspigmentation, and displacement) events. An alternative classification would include

- Allergic/hypersensitivity,

- Vascular events,

- Infective,

- Late-onset nodules or inflammation.

To ensure the optimal management of untoward events, it is prudent to have easily accessible practice protocols and algorithms as well as an excellent collegial backup system. A direct line to an ophthalmologist experienced in treating retinal artery occlusion and administering retrobulbar hyaluronidase is highly advisable. Efficient structures need to be in place for the treatment of both early- and delayed-onset reactions, and regular checks of expiry dates on emergency drugs (programmed computer prompts) should be instituted.

\section{Post-treatment checklist}

- Routinely check perfusion in the treated areas as well as areas with watershed perfusion (glabella, nasal tip, and upper lip) ensuring that makeup is not obscuring skin tone. Initial signs of vascular compromise may be subtle.

- The patient should be furnished with written posttreatment instructions and contact numbers.

- The esthetic physician/clinic should be available telephonically for 48 hours postprocedure.

- It is good practice to have a staff member call the patient the next day.

\section{Hypersensitivity}

Hypersensitivity or allergic reactions can occur when the injected filler activates an immune response. ${ }^{3,5,44}$ With earlyonset hypersensitivity reactions, check vital signs and have resuscitation measures such as adrenalin, intravenous (IV) access, and fluids in place. Cold compresses may be used for delayed onset localized angioedema, with H1-receptor antagonist for histamine-induced hypotension and the reduction in pruritus. ${ }^{15}$ H2-receptor antagonists, oral corticosteroids, or ibuprofen may be considered as additional measures (Table 2). ${ }^{7}$

\section{Vascular events}

The first symptoms of intravascular placement are often (but not always) pain and skin color change, which may be remote from the injection point. Although the first symptom of intravascular placement is often described as pain, the common addition of local anesthetics to filler formulations may
Table 2 Algorithm for early and delayed hypersensitivity reactions

\begin{tabular}{|l|l|}
\hline Hypersensitivity reactions \\
\hline Early & Delayed \\
\hline Check vital signs & Cold compresses \\
\hline Resuscitation measures: & HI-receptor antagonists \\
\cline { 2 - 2 } Adrenalin & H2-receptor antagonists \\
\cline { 2 - 2 } IV access & Leukotriene synthesis inhibitors \\
\hline \multirow{5}{*}{ Fluids } & \\
\hline & Oral corticosteroids \\
\cline { 2 - 2 } & Propranolol \\
\cline { 2 - 2 } & lbuprofen \\
\hline
\end{tabular}

Abbreviation: IV, intravenous.

obviate this sign. Vigilant observation of skin color change, which may be remote from the injection point, is mandatory. Although usually immediate, the onset has been reported to be delayed up to 24 hours. Any suspicion of inappropriate pain, skin blanching, or mottled discoloration warrants immediate cessation of injection with the application of warm compresses, injection of hyaluronidase, and massage of the affected area. The patient should be given two tablets $\left(650 \mathrm{mg}\right.$ ) of aspirin to chew and swallow. ${ }^{45}$ High-dose hyaluronidase (500-1000 IU) mixed with lidocaine in repeated hourly doses for 3 hours forms the backbone of the emergent therapy (Table 3 ). ${ }^{25}$ It is advisable to use a large bore cannula for instillation of the hyaluronidase in the subdermal plane to avoid bruising, which would confound the visual feedback of improving skin color.

For ophthalmic events, the following is suggested:

- Contact the ophthalmologist of choice directly and accompany the patient to his office.

- Respect the absolute 90-minute time frame for saving the loss of vision. ${ }^{46}$

- Have multiple vials of hyaluronidase at hand and be knowledgeable regarding reconstitution and dosage.

- Carry own hyaluronidase to the ophthalmologist.

- If possible, annotate the time of the vascular event and the visual acuity if lack of light perception (LP) or loss of vision occurs

- To facilitate accurate ophthalmological follow-up, immediate recording of vision should be annotated as no light perception (NLP), LP, hand motion (HM), and count fingers (CF), followed by a Snellen chart if available. An afferent pupillary defect should be noted if present.

- Attempt rapid ocular pulsed massage.

- Having the patient hyperventilate in a paper bag may promote retinal vessel dilation. 
Table 3 DeLorenzi's HDPH dosage and protocol

\begin{tabular}{|l|l|l|}
\hline High-dose pulse hyaluronidase \\
\hline \multirow{4}{*}{ Dosage } & Standard dosage & $500 \mathrm{IU}$ per area \\
\cline { 2 - 3 } & Lip, nose, and forehead & Act as multipliers \\
\cline { 2 - 2 } & Two areas & $\mathrm{I}, 000 \mathrm{IU}$ per hour \\
\cline { 2 - 2 } & Three areas & $\mathrm{I}, 500 \mathrm{IU}$ per area \\
\hline Protocol & - Inject at least every 60-90 minutes until skin color has normalized and capillary refill time has normalized \\
\hline - Massage to increase embolus contact with the hyaluronidase by propelling the HA distally into thinner-walled arterioles \\
\hline - Aim to complete treatment within 72 hours of onset for complete resolution \\
\hline $\begin{array}{l}\text { - Keep patient in clinic for observation and treatment until the capillary refill has improved (usually three sessions over } 3 \text { hours) } \\
\text { - Do not apply nitroglycerin paste until the offending HA has been dissolved (day } 2 \text { or } 3 \text { of treatment) as dilation of adjacent nonobstructed } \\
\text { vascular pathways can lead to the propagation of the embolus toward the orbit }\end{array}$ \\
\hline
\end{tabular}

Abbreviation: HA, hyaluronic acid; HDPH, high-dose pulse hyaluronidase.

Table 4 Algorithm for single or multiple late-onset nodules

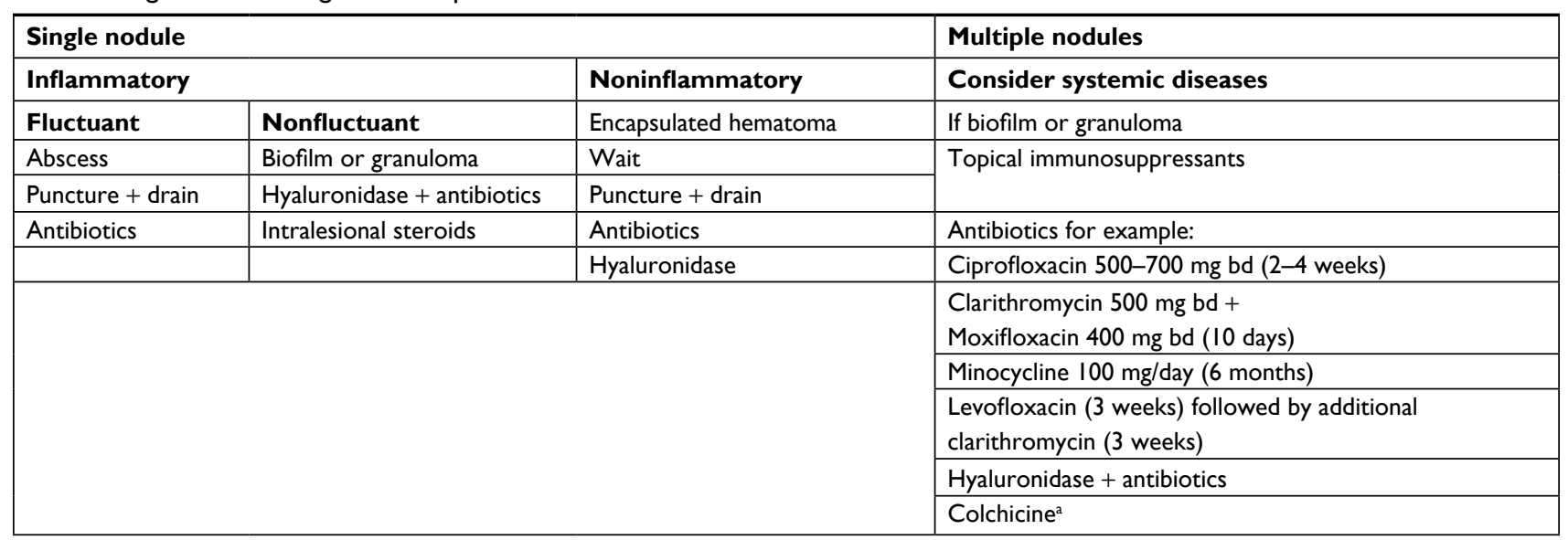

Note: anpublished data.

Abbreviation: bd, twice daily.

It is important to note that complications such as panophthalmoplegia, pulmonary embolism, and cerebral infarction have been reported after filler injections. ${ }^{47}$

\section{Infection}

Injecting dermal fillers breaches the skin barrier, thus posing a risk of infection. ${ }^{32}$ The latter can be broadly categorized as acute infections, which appear as acute inflammation or abscesses at the site of injection, or as delayed-onset chronic infections, which generally develop 2 or more weeks after initial treatment. The differential diagnosis of cellulitis vs pure inflammation is often clinically challenging in the absence of fever or abscess formation and may require aspiration, culture, and blood tests to confirm etiology. Systemic steroids, although indicated to quell inflammation, are contraindicated in cases of infection. Infection can be treated with oral antibiotics, which exert immunomodulatory and anti-inflammatory effects..$^{27,48,49}$ For additional treatment, hyaluronidase, IV antibiotics, laser, or surgical drainage of the abscess may be considered. ${ }^{14}$

\section{Late-onset nodules}

Late-onset nodules ( 4 weeks to $>1$ year posttreatment) most likely occur due to inflammatory or biofilm-related causes. ${ }^{50}$ The etiology of the nodules may be related to prolonged mechanical irritation or hematogenous seeding of relatively innocuous bacteria from a distant site (eg, dental cleaning). Binding of nonvirulent infectious agents around the time of procedure may lead to an immune response mediated via TLRs. For late-onset nodules, the use of antibiotics, hyaluronidase, topical tacrolimus $(0.1 \%)$ or pimecrolimus (1\%), and bacteriostatic/immunosuppressive agents such as hydroxychloroquine, cyclosporin $\mathrm{A}$, and methotrexate depending on the etiology of the nodules is considered (Table 4). ${ }^{5,51}$ Recently, the successful use of colchicine has also been proposed (submitted for publication).

\section{Conclusion}

This 10PP not only informs safer practice but hopefully also deepens consideration of the factors that can safeguard the field of esthetic fillers. From the importance of careful patient 
selection, through informed product choice, to vigilant procedural planning, the esthetic physician is empowered to perform optimally. The most feared complications are vascular compromise and blindness. Again, it is the detailed knowledge of facial anatomy combined with a systematic approach and the availability of appropriate algorithms that allows the esthetic physician to proceed with confidence.

As previously stated, the majority of adverse events are avoidable. Through vigilant practice, we may attempt to safeguard our patients and mitigate the threat to the field of esthetic fillers from within.

\section{Acknowledgment}

The authors would like to express thanks to Elizabeth A Rademan, Department of Physiological Sciences, and Department of Journalism, Stellenbosch University, South Africa, for the assistance, which significantly improved the manuscript.

\section{Disclosure}

The authors report no conflicts of interest in this work.

\section{References}

1. Department of Health. Review of the Regulation of Cosmetic Interventions; 2013. Available from: https://www.gov.uk/government/uploads/ system/uploads/attachment_data/file/192028/Review_of_the_Regulation_of_Cosmetic_Interventions.pdf\%5Cnhttps://www.gov.uk/ government/uploads/system/uploads/attachment_data/file/192029/ Regulation_of_Cosmetic_Intervention. Accessed September 26, 2018.

2. Signorini M, Liew S, Sundaram H, et al. Global Aesthetics Consensus: Avoidance and Management of Complications from Hyaluronic Acid Fillers-Evidence- and Opinion-Based Review and Consensus Recommendations. Plast Reconstr Surg. 2016;137(6):961e-971e.

3. Bailey SH, Cohen JL, Kenkel JM. Cosmetic medicine review article: Etiology, prevention, and treatment of dermal filler complications. Aesthetic Surg J. 2011;31(1):110-121.

4. Ibrahim O, Overman J, Arndt KA, Dover JS. Filler nodules: Inflammatory or infectious? A Review of biofilms and their implications on clinical practice. Dermatologic Surg. 2017;44(1):53-60.

5. Chiang YZ, Pierone G, Al-Niaimi F. Dermal Fillers: pathophysiology, prevention and treatment of complications. J Eur Acad Dermatol Venereol. 2017;31(3):405-413.

6. Beleznay K, Carruthers JDA, Humphrey S, Jones D. Avoiding and treating blindness from fillers: A review of the world literature. Dermatologic Surg. 2015;41(10):1097-1117.

7. de Boulle K, Heydenrych I. Patient factors influencing dermal filler complications: prevention, assessment, and treatment. Clin Cosmet Investig Dermatol. 2015;8(1):205-214.

8. Phoenix DA, Dennison SR, Harris F. Antimicrobial Peptides. Hoboken, NJ: John Wiley \& Sons; 2012.

9. Asai Y, Tan J, Baibergenova A, et al. Canadian Clinical Practice Guidelines for Rosacea. J Cutan Med Surg. 2016;20(5):432-445.

10. Beylot C, Auffret N, Poli F, et al. Propionibacterium acnes: an update on its role in the pathogenesis of acne. J Eur Acad Dermatol Venereol. 2014;28(3):271-278.

11. Beleznay K, Carruthers JD, Carruthers A, Mummert ME, Humphrey S. Delayed-onset nodules secondary to a smooth cohesive $20 \mathrm{mg} /$ $\mathrm{mL}$ hyaluronic acid filler: cause and management. Dermatol Surg. 2015;41(8):929-939.
12. Narins RS, Jewell M, Rubin M, Cohen J, Strobos J. Clinical conference: management of rare events following dermal fillers--focal necrosis and angry red bumps. Dermatol Surg. 2006;32(3):426-434.

13. Narins RS, Coleman WP, Glogau RG. Recommendations and treatment options for nodules and other filler complications. Dermatol Surg. 2009;35(Suppl 2):1667-1671.

14. DeLorenzi C. Complications of injectable fillers, part I. Aesthet Surg J. 2013;33(4):561-575.

15. de Boulle K. Management of complications after implantation of fillers. $J$ Cosmet Dermatol. 2004;3(1):2-15.

16. di Minno A, Frigerio B, Spadarella G, et al. Old and new oral anticoagulants: Food, herbal medicines and drug interactions. Blood Rev. 2017;31(4):193-203.

17. Montes JR, Juan S, Rico P. Ethnic and gender considerations in the use of facial injectables: latino patients. Plast Reconstr Surg. 2015;136(5 Suppl):32S-39S.

18. de MM. Ethnic and gender considerations in the use of facial injectables: Male patients. Plast Reconstr Surg. 2015;136(5):40-43.

19. Burgess C, Awosika O. Ethnic and Gender Considerations in the Use of Facial Injectables: African-American Patients. Plast Reconstr Surg. 2015;136(5 Suppl):28-31.

20. Rayess HM, Svider PF, Hanba C, et al. A cross-sectional analysis of adverse events and litigation for injectable fillers. JAMA Facial Plast Surg. 2018;20(3):207-214.

21. Vedamurthy M, Vedamurthy A, Nischal K. Dermal Fillers: Do's and Dont's. J Cutan Aesthet Surg. 2010;3(1):11-15.

22. Losin EAR, Anderson SR, Wager TD. Feelings of clinician-patient similarity and trust influence pain: evidence from simulated clinical interactions. J Pain. 2017;18(7):787-799.

23. Cohen JL. Understanding, avoiding, and managing dermal filler complications. Dermatol Surg. 2008;34(Suppl 1):92-99.

24. Woodward J, Khan T, Martin J. Facial Filler Complications. Facial Plast Surg Clin North Am. 2015;23(4):447-458.

25. DeLorenzi C. New high dose pulsed hyaluronidase protocol for hyaluronic acid filler vascular adverse events. Aesthet Surg J. 2017;37(7):814-825.

26. Fang M, Rahman E, Kapoor KM. Managing complications of submental artery involvement after hyaluronic acid filler injection in chin region. Plast Reconstr Surg Glob Open. 2018;6(5):1-4.

27. Funt D, Pavicic T. Dermal fillers in aesthetics: an overview of adverse events and treatment approaches. Clin Cosmet Investig Dermatol. 2013;6(1):295-316.

28. Fowler JF, Zachary CB, Rosen T, Sobell JM, Solish N, Gold LFS. Highlights of skin disease education foundation's 40th annual Hawaii dermatology seminar. Semin Cutan Med Surg. 2016;35(6):103-123.

29. Sánchez O, Rodríguez-Sureda V, Domínguez C, et al. Study of biomaterial-induced macrophage activation, cell-mediated immune response and molecular oxidative damage in patients with dermal bioimplants. Immunobiology. 2012;217(1):44-53.

30. Niamtu J. Image is everything: pearls and pitfalls of digital photography and PowerPoint presentations for the cosmetic surgeon. Dermatol Surg. 2004;30(1):81-91.

31. Travelute CR, Cartee TV. Aseptic technique. In: Robinson J, Hanke CW, Siegel D, Fratila A, Bhatia A, editors. Surgery of the skin: procedural dermatology. Amsterdam: Elsevier; 2014:40-89.

32. Wang Y, Leng V, Patel V, Phillips KS. Injections through skin colonized with Staphylococcus aureus biofilm introduce contamination despite standard antimicrobial preparation procedures. Sci Rep. 2017;7(45070):1-9.

33. Alam M, Gladstone H, Kramer EM, et al. ASDS guidelines of care: injectable fillers. Dermatol Surg. 2008;34 Suppl 1:115-148.

34. Cassuto D. Sundaram H. A problem-oriented approach to nodular complications from hyaluronic acid and calcium hydroxylapatite fillers: Classification and and recommendations for treatment. Plast Reconstr Surg. 2013;132(4):48-58.

35. Saththianathan M, Johani K, Taylor A, et al. The role of bacterial biofilm in adverse soft-tissue filler reactions: A combined laboratory and clinical study. Plast Reconstr Surg. 2017;139(3):613-621. 
36. Rzany B, DeLorenzi C. Understanding, Avoiding, and Managing Severe Filler Complications. Plast Reconstr Surg. 2015;136(5 Suppl):196S-203S.

37. Kumar N, Swift A, Rahman E. Development of "core syllabus" for facial anatomy teaching to aesthetic physicians: A Delphi consensus. Plast Reconstr Surg Glob Open. 2018;6(3):e1687.

38. Kumar N, Rahman E. Effectiveness of teaching facial anatomy through cadaver dissection on aesthetic physicians' knowledge. Adv Med Educ Pract. 2017;8(1):475-480.

39. Goodman GJ, Roberts S, Callan P. Experience and management of intravascular injection with facial fillers: Results of a multinational survey of experienced injectors. Aesthetic Plast Surg. 2016;40(4):549-555.

40. Gladstone HB, Cohen JL. Adverse effects when injecting facial fillers. Semin Cutan Med Surg. 2007;26(1):34-39.

41. Chaabane W, User SD, El-Gazzah M, et al. Autophagy, apoptosis, mitoptosis and necrosis: interdependence between those pathways and effects on cancer. Arch Immunol Ther Exp. 2013;61(1):43-58.

42. Khan TT, Colon-Acevedo B, Mettu P, DeLorenzi C, Woodward JA. An anatomical analysis of the supratrochlear artery: Considerations in facial filler injections and preventing vision loss. Aesthet Surg J. 2017;37(2):203-208.

43. Glogau RG, Kane MA. Effect of injection techniques on the rate of local adverse events in patients implanted with nonanimal hyaluronic acid gel dermal fillers. Dermatol Surg. 2008;34(Suppl 1):105-109.
44. Lemperle G, Rullan PP, Gauthier-Hazan N. Avoiding and treating dermal filler complications. Plast Reconstr Surg. 2006;118(3 Suppl):92-107.

45. Loh KTD, Phoon YS, Phua V, Kapoor KM. Successfully managing impending skin necrosis following hyaluronic acid filler injection, using high-dose pulsed hyaluronidase. Plast Reconstr Surg Glob Open. 2018;6(2):1-3.

46. Hayreh SS, Zimmerman MB, Kimura A, Sanon A. Central retinal artery occlusion. Retinal survival time. Exp Eye Res. 2004;78(3):723-736.

47. Li KT, Huang YH, Chen CH, Chou LW. Delayed-onset cerebral infarction after cosmetic facial injection using hyaluronic acid. J Formos Med Assoc. 2016;115(7):587-588.

48. Rohrich RJ, Monheit G, Nguyen AT, Brown SA, Fagien S. Soft-tissue filler complications: the important role of biofilms. Plast Reconstr Surg. 2010;125(4):1250-1256.

49. Sclafani AP, Fagien S. Treatment of injectable soft tissue filler complications. Dermatol Surg. 2009;35(Suppl 2):1672-1680.

50. King M, Bassett S, Davies E, King S. Management of Delayed Onset Nodules. J Clin Aesthet Dermatol. 2016;9(11):1-5.

51. Urdiales-Gálvez F, Delgado NE, Figueiredo V, et al. Treatment of soft tissue filler complications: Expert consensus recommendations. Aesthetic Plast Surg. 2018;42(2):498-510.
Clinical, Cosmetic and Investigational Dermatology

\section{Publish your work in this journal}

Clinical, Cosmetic and Investigational Dermatology is an international, peer-reviewed, open access, online journal that focuses on the latest clinical and experimental research in all aspects of skin disease and cosmetic interventions. This journal is included on PubMed. The manuscript management system is completely online

Submit your manuscript here: https://www.dovepress.com/clinical-cosmetic-and-investigational-dermatology-journal

and includes a very quick and fair peer-review system, which is all easy to use. Visit http://www.dovepress.com/testimonials.php to read real quotes from published authors 